\title{
Bilateral frontoparietal polymicrogyria
}

INSERM

\section{Source}

INSERM. (1999). Orphanet: an online rare disease and orphan drug data base. Bilateral frontoparietal polymicrogyria. ORPHA:101070

Bilateral frontoparietal polymicrogyria (BFPP) is a sub-type of polymicrogyria (PMG; see this term), a cerebral cortical malformation characterized by excessive cortical folding and abnormal cortical layering, that involves the frontoparietal region of the brain and that presents with hypotonia, developmental delay, moderate to severe intellectual disability, pyramidal signs, epileptic seizures, non progressive cerebellar ataxia, dysconjug ate gaze and/or strabismus. 